\title{
Multi-dimension and Multi-level Knowledge Dissemination Model under the Ubiquitous Network
}

\author{
Liu Cong ${ }^{1, a}$ \\ ${ }^{1}$ Information Technology Center, Tsinghua University, Beijing, 100084, China \\ aemail: liuc@tsinghua.edu.cn
}

\begin{abstract}
Keywords: Ubiquitous Network; Knowledge Dissemination; Multi-dimension; Multi-level; Network Teaching; Model
\end{abstract}

\begin{abstract}
Research on knowledge dissemination model under the ubiquitous network environment has become a hot research in the field of distance education in the world at present. Starting from the standpoint of knowledge dissemination and starting with the change of system state, we attempt to propose a multi-dimension and multi-level knowledge dissemination model. In the actual blended learning process, based on multi-level implementation mode and starting from the eight dimensions of blended learning system, according to the specific teaching and learning contents, we utilize diversify strategies, construct the informationization of learning environment, design learning activities, integrate teaching and learning in or out of class, and launch learning management and stereoscopic evaluation, in order to ensure competence construction of learners in aspects of cognition, emotion, motivation and interaction and the improvement of comprehensive quality, and make them become innovative talents adapted to the requirements of the times. Finally, combined with specific teaching activities of a university, we conducted practical research and designed network teaching general framework and service architecture based on cloud architecture, in order to achieve optimal support services of knowledge dissemination.
\end{abstract}

\section{Introduction}

With the development of IT technology, UN (Ubiquitous Network) environment is generally regarded as the future of humanity living environment. The core idea of UN concept is that the information technology integrates into people's daily lives with no discernible way, namely at any time and in any case can reach the Internet via wireless communication. Therefore, in the era of UN, information technology will be the same as the nervous system to become an indispensable part of social organism [1] [2].

Knowledge is the core of economic development, and has become the important resource for social progress and development. As well as knowledge dissemination is the indispensable link in knowledge progress. New information technology has promoted the development of network information environment, and has made the ways of knowledge dissemination undergo profound changes. Network knowledge dissemination has developed from the original single-mode to multi-state mode. By means of new network, knowledge has taken on a new form of ubiquitous communication. Especially, social networking, sharing and multi-channel have further promoted the ubiquitous communication of knowledge.

In universities, with the improvement of education system reform and school running patterns, the functionality and layout of universities have also produced a corresponding change, and the new education mode of universities includes open education, quality education, interdisciplinary construction and cultivation of compound talents. Under such educational mode, how to effectively carry out the dissemination of information and knowledge in the teaching activities of university teachers and students has become an important discussion topic. Therefore, we proposed a multi-dimension and multi-level knowledge dissemination model under the ubiquitous network, and designed the system framework. Through research and analysis, it is very necessary and valuable. 


\section{Related Concepts and Knowledge Dissemination Model}

Ubiquitous Network. In 1991, Mark D. Weiser, a computer scientist, proposed a new computing model beyond the desktop, Ubiquitous Computing. He believes that the purpose of ubiquitous computing is to make computers available throughout the physical environment, and to let computers as the invisible servants to make people's attention back to the tasks to be completed. On this basis, it derived the concept of UN. UN put forward the concept construction to realize the communication at any time, any place, any person, any object, and is committed to achieve the change from Electronic to Ubiquitous [3].

There are three major systems in UN technology, including intelligent terminal system, basic network technology and application layer technology [4]. Therefore, learning environment provided by UN environment is interoperable, pervasive and seamless, and make collaborators, learning content, learning services, and other elements in learning environment connect and integrate, in order to implement sharing between them and realize the purpose of ubiquitous learning, teaching and scientific research in universities.

Knowledge Dissemination Model. Educational communication is an activity, i.e. educators in accordance with the requirements for a certain purpose, select appropriate information content, through effective media channels, transfer knowledge, skills, ideas and concepts to the specific educational objects [5]. From a macro point of view, knowledge dissemination and generation process can be simply summarized as such a process, i.e. knowledge of teaching materialsknowledge of teachers - knowledge of students.

Teaching can be seen as a running process of complex system composed of teachers, students, curriculum, resources and other elements. In this process, system state in knowledge dissemination is dynamically changing. Starting from the standpoint of knowledge dissemination and starting with the change of system state, we attempt to construct a multi-dimension and multi-level knowledge dissemination model.

The knowledge dissemination in teaching is an evolution process of complex system. First, according to the changes of teaching system running status in three stages (before class, in class and after class) of teaching dissemination system, classroom teaching dissemination system in time can be divided into three relatively balanced sub-states: dissemination input, dissemination effects and dissemination operation. Secondly, support subsystem of system operation is introduced to ensure the consistency of the dissemination input and output in the system operation, and to regulate and maintain the dissemination effectiveness. The knowledge dissemination model is shown in Fig.1.

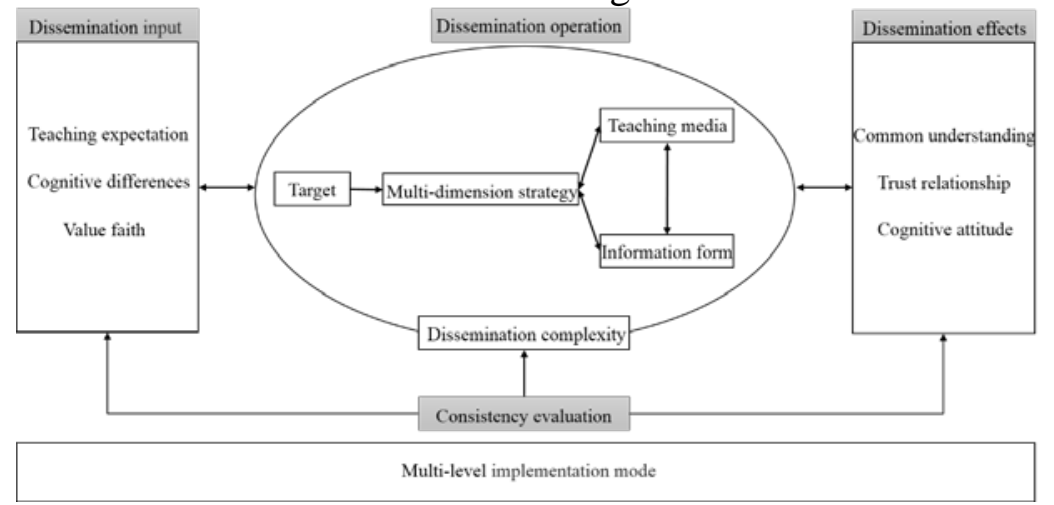

Fig.1. Knowledge dissemination model

First, the line arrows in Fig.1 do not indicate the sequential or propagating process, but represent the relationship between states or the elements. Dissemination input affects dissemination operation, while the complexity of dissemination operation state reacts dissemination input. Teachers temporarily change the teaching preset, as a result reaching dissemination effects beyond the preset. This is the full embodiment of teacher's teaching wits.

Second, the state of dissemination effects has two identities: one is result state and another one is expectation state. It is not only the destination of knowledge dissemination, but also the starting 
point of knowledge dissemination. The process of knowledge dissemination is composed of such processes mutually series constituted. This fully shows that knowledge dissemination is a progressive process, in which the knowledge of students and teachers is proved and confirmed.

Third, dissemination operation state is with high dynamic complexity. This complexity comes from the interaction between the cognitive complexity and the emotional complexity of the students, which is the nonlinear factor in the system. Many factors of disseminators including preference on the dissemination theme, understanding level of receivers, social status, social identity and cultural background influence the dissemination effects, while reflect the emotional impacts on those who pass the disseminators.

Fourth, evaluation system as the coordination mechanism of system elements is a support system to achieve the system state change. From a large scale perspective, knowledge dissemination changes between various states, such as (expected) dissemination effects - dissemination input dissemination operation - dissemination effects. During these changes, evaluation system plays a role in coordinating and monitoring.

\section{Multi-level Implementation Mode}

With the advancement of university education informationization and the development of university digital campus construction, blended learning has become an important part of teaching reform in higher education. Blended learning mode application based on network teaching platform will provide a new way for the teaching reform in university. Therefore, we present a multi-level implementation mode of blended learning shown in Fig.2, including taking organization of learning activities as the center level, taking classroom as the center level, taking system as the center level and taking evaluation as the center level.



Fig.2. 4A-based multi-level implementation mode

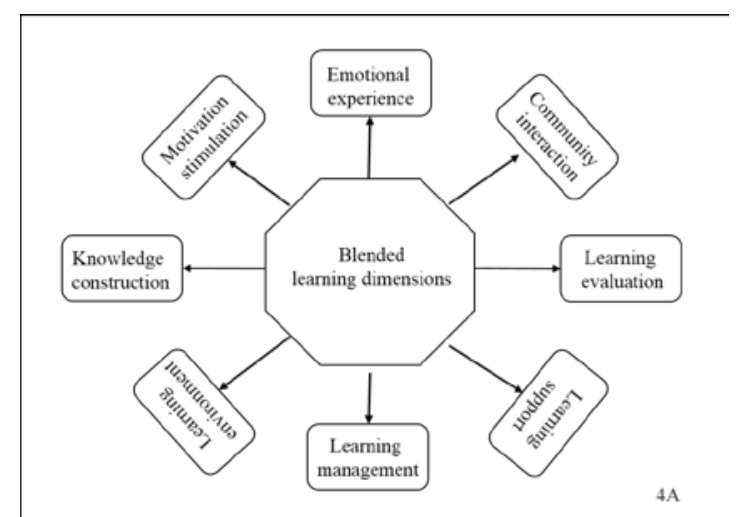

Fig.3. Blended learning dimensions

Taking Organization of Learning Activities as the Center Level. Taking organization of learning activities as the center level mainly consists of pre-analysis and organization of learning activities.

Pre-analysis is the starting point of teaching and learning, mainly involving analysis on learner's profile, analysis on teaching contents, determination of teaching objectives, arrangement of teaching plan, design of curriculum evaluation and other aspects. Based on analysis of learner's profile and teaching contents, determine reasonable teaching goals, arrange teaching plans, consider curriculum evaluation design in the planning process, and ultimately determine the methods and contents of curriculum evaluation.

Organization of learning activities is the core of learning implementation mode, and is a series of learning activities which are completed under the teachers' organization. Organization of learning activities is the guarantee for the effective implementation of learning activities, which has a significant role in promoting knowledge construction, emotional experience, motivation stimulation, and social community collaboration interaction for learners. It includes learning activity analysis design, learning situation creation, teaching strategy design, media delivery design, learning activity evaluation. 
Taking System as the Center Level. Taking system as the center level mainly refers to constructive learning environment design.

Constructive learning environment design is the support of multi-level implementation mode, and network teaching platform is the basis of implementation environment. We choose 4A (Anyone, Anytime, Anywhere, Anything) platform to design constructive learning environment. The design concept of 4A is that any person at anytime, anywhere, can learn anything he wanted. The first step of constructive learning environment design is to select the appropriate network teaching platform and to set the relevant functions according to the curriculum needs. The next step is to design and develop online courses and learning resources, and then these resources are organized, reorganized and stored. Finally, a variety of platform-based teaching and learning activities should be continuously enriched and improved.

Taking Classroom as the Center Level. Taking classroom as the center level mainly includes the implementation of classroom teaching and 4A-based online learning after class.

Classroom teaching is the key link of multi-level implementation mode. Classroom teaching starts from introductory course, develops blended learning environment training for students, stimulates and maintains learning motivation of students, based on the delivery of major and difficult knowledge carries out learning research projects, and encourages students to discuss and interact. At the same time, teachers should pay attention to face to face counseling and answering questions, exert betimes character of classroom assessment, promote the learners' cognition, emotion and interaction, in order to lay a good foundation of online learning after class.

Online learning is a continuation of classroom teaching, especially to provide a space for the organization of learning activities. Online learning needs to guide students to master the related operations in the network learning environment. Students can autonomously learn using online courses, actively participate in online discussions, and consciously complete online homework and online testing. Teachers and teaching assistants should be qualified online tutors to guide students to conduct online experiments and to monitor group-based online collaborative learning. Finally, teachers and students can use 4A platform to develop online evaluation.

Taking Evaluation as the Center Level. Taking evaluation as the center level mainly includes stereoscopic evaluation and evaluation-based revision.

Stereoscopic evaluation mainly includes diversification of evaluation subject, diversification of evaluation method, the combination of online evaluation and classroom evaluation, individual differences evaluation. Stereoscopic evaluation reflects the idea of developmental evaluation, reflecting the transformation from examination concern to growing concern of learners, from result concern to process concern, from quantitative evaluation to the combination of quantitative and qualitative evaluation system. In the support of information technology, the implementation of learning-process-oriented developmental teaching evaluation will undoubtedly play an important role in promoting the transformation of teaching evaluation system of higher education. This developmental teaching evaluation specifically embodies portfolio assessment and examination assessment. Portfolio assessment is a developmental evaluation methodology favored under the network environment, and its main function is save, reflection and communication. Examination assessment includes traditional classroom test papers and 4A-based online evaluation.

Evaluation-based revision is a kind of evaluative feedback, instead of just information to provide informative feedback. Its purpose is to allow students to give feedback on their progress, in order to enhance and improve their learning. Evaluation-based revision is a revision of any level or any link of multi-level implementation mode. In the specific implementation process, based on the specific revision feedback, we should timely amend or adjust a specific link of the mode, in order to make the entire mode more flexible. 


\section{Multi-dimension Teaching Strategy}

The aim of teaching strategy is to design an economical and effective teaching, and to produce reliable results. We attempt to effectively mix the methods and strategies from eight dimensions including knowledge, emotion, motivation, interaction, environment, management, support and evaluation. Multi-level implementation mode is only a reference, and how to enrich the various links depends on diverse and effective methods and strategies to achieve. The blended learning dimensions is shown in Fig.3.

Knowledge, emotion, motivation and interaction are both contents and goals, while environment, management, support and evaluation are the support to realize knowledge construction, emotional experience, motivation stimulation and community interaction. In each dimension of blended learning, we have put forward practical strategies and methods to make blended learning do better based on the reference of implementation mode. Therefore, multi-dimension teaching strategy is a guarantee mechanism in the implementation of blended learning mode.

Knowledge Construction. Knowledge construction is the foundation of education and teaching, whether in the classroom teaching or in the network learning. Especially in the process of blended learning, only knowledge construction as the basis can ensure emotional experience, motivation stimulation and community interaction conduct meaningfully and reduce the appearance of deviation. Based on practical experience in teaching, we propose the idea of knowledge construction as "from sharing to symbiosis" shown in Fig.4, which reveals the common tendency of knowledge construction in the information age. In the digital learning environment, on the basis of individual knowledge sharing, there has been gradually forming learning community with group participation, in order to promote the internalization of individual knowledge and the growth of collective knowledge.

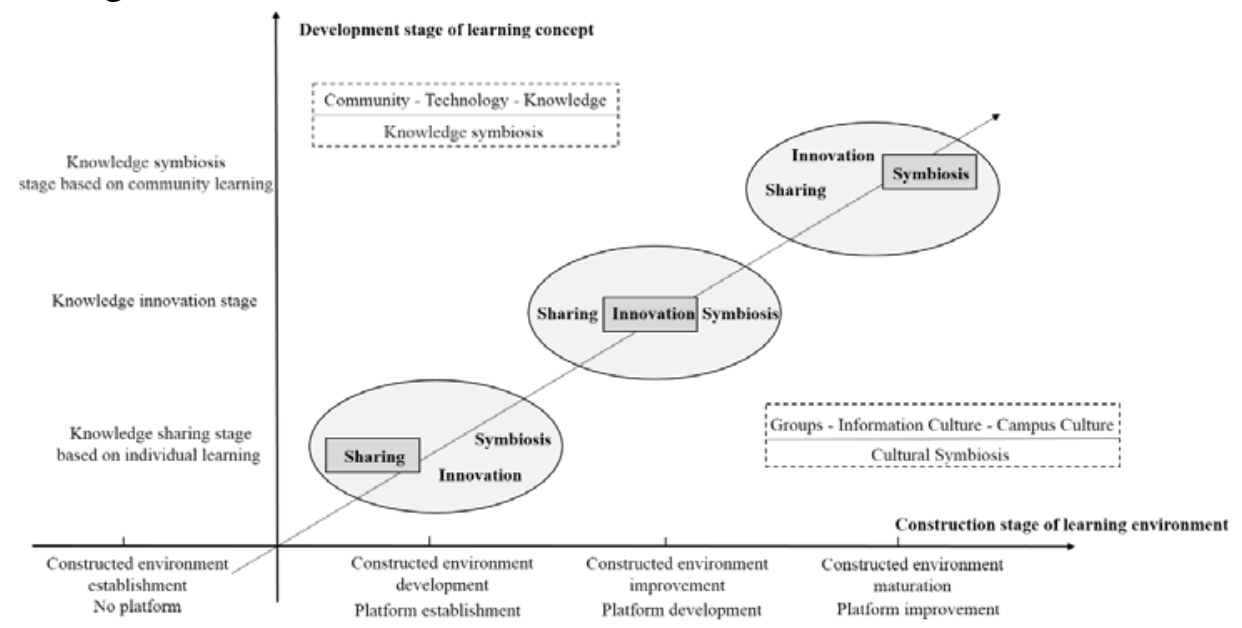

Fig.4. The evolution of knowledge construction concept

Emotional Experience. Learning is a process of knowledge construction, but also a process of emotional experience. The learning process is influenced by various emotional factors, because teachers and learners in the process of knowledge construction are making a variety of emotional activities, producing a variety of emotional experience, thereby affecting learning effectiveness and the formation of participants' attitude, motivation, values and other emotional factors. To solve these problems, we can use the following methods to facilitate learners' emotional experience:

- Strengthen teaching scene design.

- Integrate online learning and classroom teaching.

- Convert roles between teachers and students, strengthen communication, truly achieve leading subject, and richen emotional experience.

- Establish learning community under the network environment, and adopt a variety of ways to promote emotional communication of the community members.

Motivation Stimulation. The so-called motivation is a power to stimulate, maintain and make the 
behavior point to a specific purpose. This power can enable learners to engage in learning tasks, to focus on a specific learning objective or to do extra work in a specified task. The factors that affect the students' motivation include learning task, teachers and students themselves, such as their interests, autonomy, self-efficacy, attribution and intelligence view. In the actual teaching process, teachers can through observing the students' behaviors infer their motives, then adopt corresponding methods to promote students' self-confidence and to promote students to participate, in order to stimulate and maintain the learning motivation of the students.

Community Interaction. Blended learning community is based on the curriculum objectives, to promote effective communication between learners, to guide the learners to master a variety of collaborative skills, to improve the collaboration efficiency, to get meaning construction, to create a good learning atmosphere for mutual cooperation, and to achieve the common growth of ability. To realize the efficient collaboration, we have to master appropriate collaboration skills and use appropriate strategies to improve the efficiency of community cooperation, mainly including the creation of a good learning situation, teachers' positive guidance in the community construction, proper settings of population size, and the effective management of community conflict.

Learning Environment. The development of teaching/learning activities and the implementation of teaching evaluation measurement is underway in a certain learning environment. Blended learning can create vivid information learning environment for learners to provide rich learning resources, tools and interpersonal relationship support.

Learning Support. Learning support comes from the field of distance education, whose services are throughout the entire process of blended learning. Thus, learning support has the guarantee effect on the implementation of blended learning mode. For blended learning, it is necessary for learning support since the introduction of E-Learning component. Learning support of blended learning comes from teachers, teaching assistants, students in the same team or other teams, mainly including emotional support, curriculum support, and technical support.

Learning Management. The learning management strategy refers to the strategies for guiding and controlling organization and transmission of teaching implementation, which lead to the arrangement of teaching events and the transmission mechanism of these events. The learning management of blended learning advocates comprehensive teaching management integrating classroom and online education, encourages students to participate in management, and achieves a variety of effective management based on network teaching platform.

Learning Evaluation. Stereoscopic learning evaluation mainly includes flexible application of classroom assessment and implementation of portfolio assessment.

Classroom assessment is student-centered and classroom-oriented, mainly including direct evaluation and timely feedback. According to scholars' research, classroom assessment can be divided into three categories from easy to difficult. The first category is the assessment of learners' knowledge and skills related to curriculum. The second category is the assessment of learners' attitudes, values and self-consciousness. The third category is the assessment of learners' teaching reaction. In the actual teaching and learning practice, flexible application of classroom assessment timely optimizes teaching and learning according to the actual situation.

The composition of e-portfolio mainly comes from some process data and materials generated in the classroom teaching and network learning, including learning objectives, learning activities, growth data, stage works, summary reflection and evaluation. The portfolio composition is of great flexibility, which can be different determined by learning contents, purposes, submission objects and specific circumstances of learners.

\section{System Architecture}

Combined with specific teaching activities of a university, network teaching environment supported by information technology is to establish informatization environment to support blended-learning-oriented mode, providing teaching scenario creation, issues exploring and collaborative workshops, realizing mobile-based curriculum teaching support, activity-based research-oriented teaching support and SNS-based interactive collaborative teaching support. The 
construction objective is to build integration and information teaching environment with teaching activities oriented and multiple teaching modes integrated, providing interactive collaborative instructional services for teachers and students and supporting the application practice of multi-dimension and multi-level knowledge dissemination model. Network teaching general framework based on cloud architecture is shown in Fig.5 and network teaching service architecture is shown in Fig.6.

\section{Conclusion}

Universities are the most centralized place of knowledge resources and human resources. Through the research and analysis on information and knowledge dissemination of teachers and students in the teaching activities, we present a multi-dimension and multi-level knowledge dissemination model. Combined with ubiquitous network technology, we construct a somewhat competent multi-level implementation mode of blended learning based on 4A network teaching platform, analyze university blended learning strategy from eight dimensions, and design network teaching general framework and service architecture based on cloud architecture, in order to enable the coordination among knowledge disseminators, knowledge recipients, knowledge base and knowledge dissemination channels to achieve a better state, and form an effective perfect knowledge dissemination system and propagation network between universities and society.

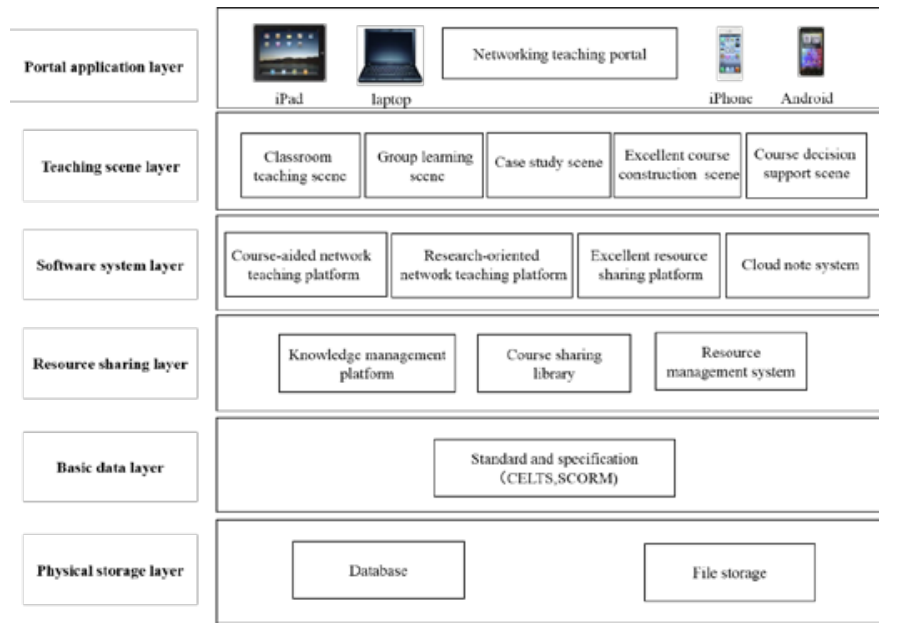

Fig.5. Network teaching general framework based on cloud architecture

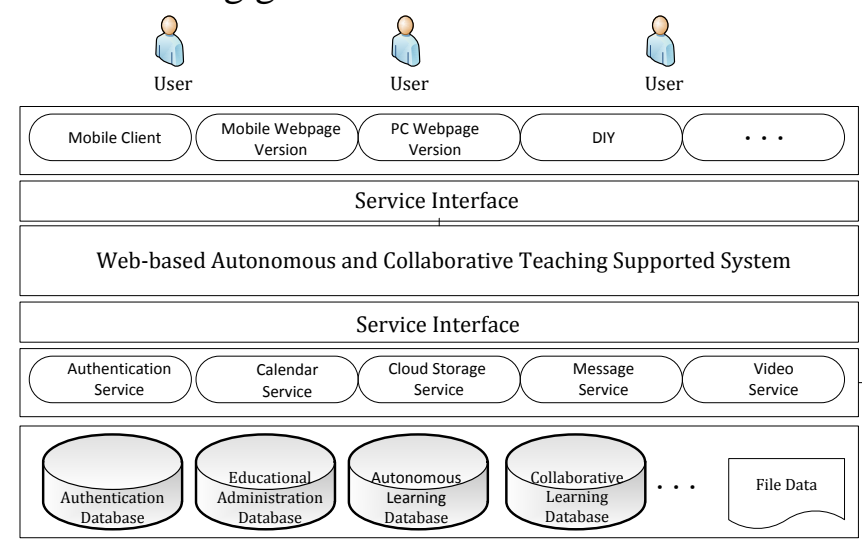

Fig.6. Network teaching service architecture

\section{References}

[1] Saha D, Mukherjee A. Pervasive Computing: a Paradigm for the 21st Century [J]. Computer, 200336 (3) 25-31.

[2] Zhang Ping, Miao Jie, Hu Zheng, Tian Hui. A Survey of Ubiquitous Network [J]. Journal of 
Beijing University of Posts and Telecommunications, 201033 (5) 1-6.

[3] Weiser M. The Computer for 21st Century [J]. Scientific American, 1991265 (3) 94-104.

[4] Jiang Qing, He Zheng-juan, Tang Lun. Key Technique and Prospects of Ubiquitous Network [J]. Communications Technology, 200841 (12) 181-182.

[5] Nan Guo-nong, Li Yun-lin. Educational Communication (Second Edition). Higher Education Press, 2005.8. 